\title{
Pediatrics \& Neonatal Biology Open Access
}

\section{Fraser Syndrome with Major Hydrocephalus}

\author{
Bennaoui $\mathrm{F}^{1,2 *}$, El Idrissi Slitine $\mathrm{N}^{1}, 2$, Jalal $\mathbf{H}^{3}$, Mouaffak $\mathbf{Y}^{4}$ and \\ Maoulainine FMR ${ }^{1,2}$ \\ ${ }^{1}$ Neonatal Intensive Care Department, Mohammed VI University Hospital and Research, \\ Morocco \\ ${ }^{2}$ Marrakech School of Medicine, Cadi Ayyad University, Morocco \\ ${ }^{3}$ Radiology department, University Hospital Mohamed VI, Morocco \\ ${ }^{4}$ Pediatric Intensive Care Medicine, Cadi Ayyad University, Morocco
}

*Corresponding author: Bennaoui F, Neonatal Intensive Care Department, Mohammed VI University Hospital and Research and Team for Childhood, Health and Development, Marrakech School of Medicine, Cadi Ayyad University, Marrakech, Morocco, Email: fatihabennaoui@yahoo.fr

\begin{abstract}
Fraser syndrome (Cryptophthalmos syndrome) is a rare malformative genetic syndrome. Cryptophthalmos is one of the most common features. Etiopathogenesis is controversial and the management is multidisciplinary. We report a case of Fraser syndrome with a review of the literature. The newborn was hospitalized in neonatal unit care, the University Hospital Mohamed VI, Marrakesh. With a similar case in siblings. The diagnosis was based on two major criteria: cryptophthalmos, syndactyly and a minor criterion: the labio-sphenoidal cleft. In addition, there was a major hydrocephalus with a reduction of the cerebral parenchyma. The karyotype was normal. The treatment required a multidisciplinary approach, our patient was not operable. Prenatal diagnosis is essential to make the diagnosis in time and to make a therapeutic decision. Fraser syndrome remains a major surgical and aesthetic challenge, particularly in developing countries.
\end{abstract}

Keywords: Cryptophthalmos; Fraser syndrome; Hydrocephalus; L-sphenoidal cleft; Syndactyly

\section{Introduction}

Fraser syndrome (Cryptophthalmos syndrome) is a rare malformative genetic syndrome described for the first time in 1962 by the British geneticist GR Fraser [1].
Its incidence is 0.043 per 10,000 live births, with autosomal recessive transmission [2].

Cryptophthalmos is one of the most frequent symptoms of this syndrome $(93 \%$ of cases) other 


\section{Pediatrics \& Neonatal Biology Open Access}

symptoms include: syndactyly, abnormal genitalia, malformations of the nose, ear and larynx, renal agenesis, clefting, skeletal defects, umbilical hernia, and mental retardation that develops later in survivors. Etiopathogenesis is always controversial and the management is multidisciplinary [3].

The authors report a case of Fraser syndrome with major hydrocephalus in order to recall the genetic, pathogenic, clinical and therapeutic aspects of this syndrome.

\section{Case Report}

We report the case of a female newborn, hospitalized in Intensive Neonatal Unit, Mohamed VI University Hospital, Marrakesh.

The parents were non-consanguineous; there was a similar case in siblings: a sister who died on the first day of life, having the same facial malformations according to the parents.

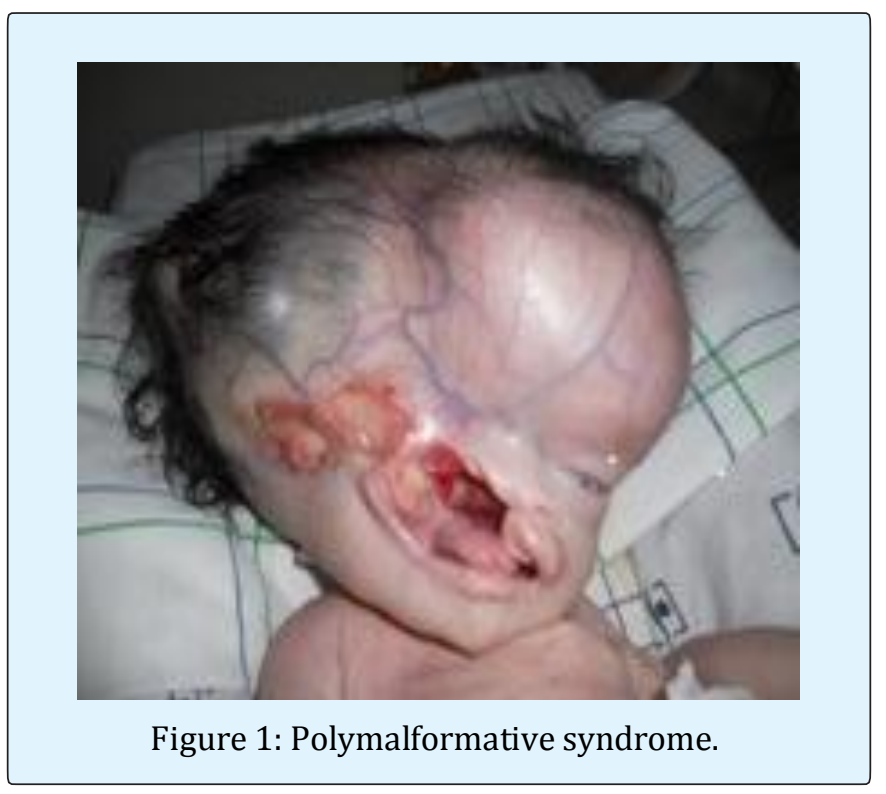

The clinical examination had noted a polymalformative syndrome (Figure 1), including: a macrocrania, with a cranial perimeter at $48 \mathrm{~cm}$ ( $>97$ th percentile), a labiosphenoidal cleft. On the right eye: incomplete cryptophthalmos with the presence of an upper eyelid, without a palpebral fold and without an eyeball. In the left eye: aniridia.

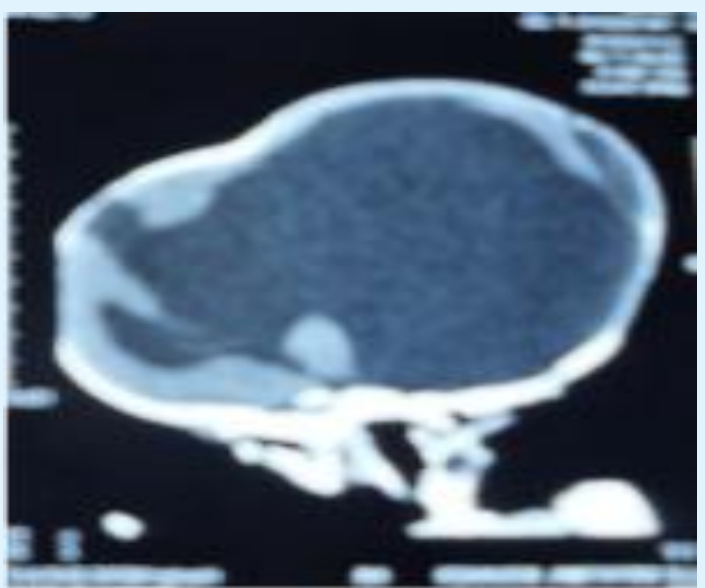

Figure 2: The cerebral CT scan showed a major hydrocephalus with a reduction of the cerebral parenchyma and confirmed the labio-sphenoidal cleft.

No other abnormalities in within the clinical examination, abdominopelvic ultrasound and echocardiography were free from abnormalities. The karyotype was normal.

The diagnosis of Fraser syndrome was based on two major criteria: cryptophthalmos and syndactyly and a minor criterion: the labio-sphenoidal cleft.

The treatment of our patient required a multidisciplinary approach, she was not operable. The evolution was fatal after 3 months.

\section{Discussion}

Fraser Syndrome (Cryptophthalmos-Syndactyly Syndrome) is a Rare Autosomal Recessive Polymalformative Syndrome; its Etiopathogenesis is Controversial [4]. It could be due to a primary abnormality of eyelid formation with corneal and conjunctival epithelium metaplasia, a partially formed eyelid refusions- Or due to a failure of programmed cell death that would lead in utero to the opening of temporarily closed areas like: eyelids, fingers, vagina, toes...

Karyotype is normal in this syndrome; recent research has led to the identification of the responsible gene: FRAS1 and research is under way to identify other genes 


\section{Pediatrics \& Neonatal Biology Open Access}

and their homozygous mutations [5]. About $15 \%$ of the children described in the literature are born of consanguineous couples and the history of siblings with this syndrome is described [6]. Its diagnosis is clinical, with major criteria and minor criteria [7].

The major criteria are: cryptophthalmos, syndactyly or genital abnormality. Minor criteria include ear abnormalities, nose abnormalities, larynx and / or palate anomalies, skeletal abnormalities, umbilical hernia, renal agenesis and mental retardation.

The diagnosis is made in the presence of two major criteria and one minor criterion, or a major criterion and four minor criteria. In general, the malformations associated with this syndrome are multiple and diverse. Cryptophthalmos is the cardinal sign, present in 93\% of cases. It is usually bilateral and complete, but its absence does not exclude the diagnosis. Syndactyly is also present in $54 \%$ of cases. Other associated ocular malformations include ankyloblepharon, lacrimal abnormalities, microphthalmia and anophthalmos [8].

\section{Many other Malformations have been Described in this Syndrome}

Otorhinolaryngology malformations (ear dysplasia, transmission deafness: very common sign, bifid nose, broad nose root, laryngomalacia, laryngeal atresia and chest atresia), urogenital malformations (Renal agenesis, unilateral or bilateral kidney hypoplasia, hypospadias, epispadias, testicular ectopia, micropenis, bicorn uterus and hymenal imperforation), anal imperforation. Associated lesions are more rare, cerebral and neurological malformations such as microcephaly, myelomeningocele, encephalocele and exencephaly as well as cardiac abnormalities [9].

Our patient presented a hydrocephalus associated with 2 major criteria: cryptophthalmos and syndactyly and a minor criterion: the labio-sphenoidal cleft.

Treatment of manifestations: Treatment by a multidisciplinary team when possible; antiepileptic drugs can help decrease the frequency and intensity of seizures; Feeding difficulties and failure to thrive may be managed with gastrostomy tube placement and Nissen fundoplication if gastroesophageal reflux and vomiting are issues. Thickening of feeds and upright positioning after feeding may be helpful to alleviate gastroesophageal reflux. To achieve the best growth in the child, the quality of the feeds is more important than the quantity.
The treatment of hydrocephalus is essentially neurosurgical. He must be curative and etiological. It sometimes involves directly reducing the secretion of CSF at the level of ventricular or more often to bypass an obstacle or resorption disorders by a bypass system. The diversion systems allow to deriver the LCR cavities ventricular to the resorption areas either intracranial (internal bypass) or extracranial (external derivations). External derivations are essentially divided into ventricular bypass peritoneal, ventriculo-atrial and lumbar peritoneal, the last two being often used in case of failure or impossibility of ventricular bypass Peritoneal. Placement of a ventriculo-peritoneal shunt may be necessary in children with HPE and hydrocephalus. In older children, surgical repair of cleft lip and/or palate may be indicated. For children with cleft lip and/or palate, referral to a specialized cleft or craniofacial clinic is recommended. Onset of new neurologic findings or deterioration warrant evaluation for seizures and/or hydrocephalus and/or shunt malfunction. Such evaluation would include vital sign monitoring, neurologic examination, EEG, and MRI. A major aspect of treatment is support and counseling of the parents [10]. Treatment requires a multidisciplinary approach, and plastic surgery remains the only treatment.

\section{Conclusion}

Fraser syndrome remains a major surgical and aesthetic challenge, particularly in developing countries. Need for prenatal diagnosis in order to decide on appropriate management.

Conflict of Interest: The authors declare that they have no conflict of interests.

\section{References}

1. Fraser GR (1962) Our genetical "load": a review of some aspects of genetical variation. Ann Hum Genet Lond 25(4): 387-415.

2. De Bernardo G, Giordano M, Di Toro A, Sordino D, De Brasi D (2015) Prenatal diagnosis of Fraser syndrome: a matter of life or death? Ital J Pediatr 4: 86.

3. Van Haelst MM, Scambler PJ, Fraser Syndrome Collaboration Group, Hennekam RC (2007) Fraser syndrome:a clinical study of 59 cases and evaluation of diagnostic criteria. Am J Med Genet A 143A (24): 3194-3203. 


\section{Pediatrics \& Neonatal Biology Open Access}

4. Duke Elder S (1964) Congenital anomalies of the ocular adnexa. In: System of ophthalmology, vol III. Normal and Abnormal development, part2. Congenital deformities. AAMC 39(3): 829-833.

5. Vogel MJ, Van Zon P, Brueton L, Gijzen M, Van Tuil MC, et al. (2012) Mutations in GRIP1 cause Fraser syndrome. J Med Genet 49(5): 303-306.

6. Slavotinek AM, Tifft CJ (2002) Fraser syndrome and cryptophthalmos. Review of the diagnostic criteria and evidence for phenotypic modules in complex malformation syndromes. J Med Genet 39(9): 623633.

7. Thomas IT, Frias JL, Felix V, Sanchez de Leon L, Hernandez RA, et al. (1986) Isolated and syndromic cryptophthalmos. Am J Med Genet 25(1): 85-98.
8. Allali B, Hamdani M, Lamari H, Rais L, Benhaddou M, et al. (2006) Syndrome de Fraser: À propos d'un cas. J Fr d'Ophtalmol 29(2): 184-187.

9. Gattuso J, Patton MA, Baraitser M (1987) The clinical spectrum of the Fraser syndrome: report of three new cases and review. J Med Genet 24(9): 549-555.

10. Benjamin D Solomon, Andrea Gropman, Maximilian Muenke (2000) Holoprosencephaly Overview. In: Adam MP, Ardinger HH, Pagon RA, Wallace SE, Bean LJH, Stephens K, Amemiya A, (Eds.), GeneReviews $®$ [Internet], University of Washington, USA. 